\title{
BRCA1/2 Mutation Testing Among Adult Women With HER2-Negative Advanced Breast Cancer: Results From a Multi-Country, Real-World Study
}

Michael Patrick Lux ( $\sim$ m.lux@vincenz.de)

St. Vincenz Krankenhaus GmbH https://orcid.org/0000-0002-2781-2178

Katie Lewis

Adelphi Real World

Alex Rider

Adelphi Real World

Alexander Niyazov

Pfizer Inc.

\section{Research Article}

Keywords: HER2-negative breast cancer, BRCA1, BRCA2, PARP inhibitor, TNBC, genetic testing

Posted Date: July 8th, 2021

DOI: https://doi.org/10.21203/rs.3.rs-682449/v1

License: (c) (i) This work is licensed under a Creative Commons Attribution 4.0 International License. Read Full License 


\section{Abstract}

Purpose: We assessed real-world patient demographics and breast cancer susceptibility genes 1 or 2 (BRCA1/2) mutation testing rates among adult women with human epidermal growth factor receptor 2 (HER2)-negative advanced breast cancer $(A B C)$.

Methods: Oncologists across the US and EU5 abstracted data from medical charts for 8-10 consecutive adult women presenting with HER2-negative $A B C$ in 2015 and 2017. BRCA1/2 mutation (germline and/or somatic) testing was analysed overall and stratified by factors: region; year of data collection; hormone receptor (HR) status; age group; practice setting.

Results: Records on 6161 adult women with HER2-negative $A B C$ were provided by 742 oncologists. Overall, $28 \%$ of women with $A B C$ received $B R C A 1 / 2$ mutation testing. Compared with patients tested for $B R C A 1 / 2$ mutations, untested patients were more likely to be aged $\geq 45$ years, have HR-positive/HER2-negative $A B C$, have no known family history of breast/ovarian cancer, and be postmenopausal (all $P<0.0001$ ). BRCA1/2 mutation testing rates were significantly lower in the EU5 versus US ( $21 \%$ vs $50 \% ; P<0.0001)$. Significantly lower $B R C A 1 / 2$ testing rates were observed in women aged $\geq 45$ versus $<45$ years, women without versus with a known family history of breast/ovarian cancer and women with HRpositive/HER2-negative ABC versus advanced TNBC (all $P<0.0001$ ).

Conclusions: BRCA1/2 mutation testing rates were low, and disparities were observed in demographics and clinical characteristics among patients who received a BRCA1/2 mutation test versus untested patients. Consistent with updated international guidelines, opportunities exist to increase $B R C A 1 / 2$ mutation testing, particularly in patients aged $\geq 45$ years, with HR-positive/HER2-negative $A B C$, or without a known family history of breast/ovarian cancer.

\section{Highlights}

- BRCA1/2 mutation testing in women with HER2-negative advanced breast cancer was low

- Testing rates were significantly lower in European countries than in the US

- Disparities in BRCA testing rates were observed

- Age $\geq 45$ years, no family history and HR-positive were linked to lower testing rates

- Opportunities exist to increase BRCA1/2 mutation testing as per updated guidelines

\section{Introduction}

Mutations in breast cancer susceptibility genes 1 or $2(B R C A 1 / 2)$ are associated with an increased risk of developing breast and ovarian cancers, and have been linked to other tumor types, including ovarian, prostate and pancreatic cancer [1-3]. In the US and Europe, treatment recommendations and guidelines for human epidermal growth factor receptor 2 (HER2)-negative advanced breast cancer (ABC) include both non-targeted (e.g., platinum-based chemotherapy) and targeted therapies for germline BRCA1/2-associated ABC [4-6]. Recently, two poly(ADP-ribose) polymerase (PARP) inhibitors, talazoparib and olaparib, demonstrated significant improvements in progression-free survival, a manageable adverse-event profile, and favourable patient-reported outcomes compared with physician's choice of chemotherapy in two randomised Phase III trials $[7,8]$. Both agents have been approved in the US and Europe as monotherapy for the treatment of patients with deleterious or suspected deleterious germline BRCA1/2-mutated HER2-negative locally advanced and/or metastatic breast cancer [9-14]. Consensus guidelines on genetic screening for breast cancer (BC) were subsequently expanded to reflect the clinical utility of germline $B R C A 1 / 2$ mutation status for identifying candidates for PARP inhibitor therapy and platinum agents $[4,5,15,16]$. 
In addition to guiding treatment decisions, germline $B R C A 1 / 2$ mutation testing can help identify familial risk and offer preventive measures to healthy relatives [17]. Identification of risk may also be important for early diagnosis of cancer, planning intensified local follow-up care of the breast, and, if necessary, initiation of prophylactic surgery [16, 17]. In the prospective PRAEGNANT registry, $5.0 \%$ of patients with unselected $A B C$ had a germline $B R C A 1 / 2$ mutation regardless of family history [18], with germline $B R C A 1 / 2$ mutations occurring more frequently in patients with triple-negative $B C$ (TNBC) than in those with hormone receptor (HR)-positive disease $[18,19]$. Therefore, understanding $B R C A 1 / 2$ mutation status has a substantial impact on oncological care.

Historically, rates of $B R C A 1 / 2$ mutation testing among women with $\mathrm{BC}$ reported in the US and Europe have been low. According to a study linking data from a US Surveillance, Epidemiology, and End Results (SEER) registry with genetic testing results, only $24.1 \%$ of women diagnosed with BC between 2013 and 2014 had germline testing results for pathogenic variants, including $B R C A 1 / 2$ [20]. For women with a personal history of $B C$ meeting $\geq 1$ specific eligibility criterion, one study using pooled data sets from 2005, 2010 and 2015 found that $29.0 \%$ of patients discussed, $20.2 \%$ were advised to undergo, and $15.3 \%$ underwent genetic testing for cancer risk [21]. Another US study reported that $16.7 \%$ of patients with metastatic BC diagnosed between 2011 and 2018 had germline testing results for BRCA1/2 mutations [22]. Limited published data are available for Europe, although the results of a study using abstracted data from medical charts in the US, the European Union (EU) 4 (France, Germany, Spain and Italy) and Israel found that germline BRCA1/2 mutation testing rates in patients with HER2-negative ABC in 2019/2020 were significantly lower in the EU4 than in the US and Israel ( $26 \%$ vs $45 \%$ [ $P=0.0008]$ and vs $97 \%$ [ $P<0.0001]$, respectively) [23]. Recently, consensus guidelines have expanded to recommend $B R C A 1 / 2$ mutation screening $[4,5,15-17,24-27]$, and most oncologists in the US and Europe now have access to targeted treatments [23].

The current study assessed real-world BRCA1/2 (germline and/or somatic) mutation testing rates among adult women with HER2-negative ABC in the US and in France, Germany, Italy, Spain and the UK (EU5). The study used data collected in 2015 and 2017, and therefore provides historical baseline BRCA1/2 mutation testing rates before the US and EU approvals of olaparib and talazoparib for germline BRCA1/2-mutated HER2-negative locally advanced and/or metastatic $B C[9,11,12]$, and predates some of the more recently expanded guidelines on genetic screening for $B C[4,5$, $15-17,24,26,27]$. Therefore, the results of this study can be used as a baseline reference to monitor $B R C A 1 / 2$ mutation testing rates.

\section{Methods}

\section{Study design and population}

Oncologists were recruited to abstract data from patient medical charts and complete patient record forms for adult women with HER2-negative ABC treated in the US and EU5. Data were abstracted from medical charts for the next 8-10 consecutive adult women presenting with HER2-negative ABC in 2015 and 2017. Oncologists were asked whether each patient had undergone any test for a germline and/or somatic BRCA1/2 mutation (information on the type of test, i.e., germline or somatic, was not collected). Data were collected in two waves (February to May 2015, and March to July 2017) and combined for common variables (region, HR status, age group, practice setting) where questions and answer categories were comparable across both years. Oncologists were reimbursed for their participation.

A geographically representative sample of oncologists was recruited, along with patients with $A B C$ treated in routine clinical practice. Only oncologists treating patients with $A B C$ were eligible. Oncologists were required to be actively involved in the prescribing decisions for patients with $A B C$ (Stage IIIb/c-IV) and to consult with a minimum of three patients with $A B C$ per week. Patient inclusion criteria included female sex, age $\geq 18$ years at data collection, and 
histologically or cytologically confirmed ABC. Oncologists were asked to exclude records for patients involved in clinical trials.

Data were collected in such a way that patients and physicians could not be identified directly; all data were aggregated and de-identified before receipt. Data collection in the 2017 wave received ethical approval from the Freiburger EthikKommission International and the Western Institutional Review Board.

\section{Analysis methods}

Testing for germline and/or somatic BRCA1/2 mutations was assessed for the overall cohort and stratified by region (US vs EU5); region by year (2015 vs 2017); known family history of breast or ovarian cancer (yes vs no); region (US vs EU5), HR status (HR-positive/HER2-negative vs TNBC) and age groups ( $<45,45-54,55-64$ and $\geq 65$ years); known family history of breast or ovarian cancer by HR status and age group; and HR status, age group and practice setting (academic medical centre vs non-academic medical centre/community oncologist) by year. Differences in demographics and clinical characteristics among women who were tested or not tested for germline and/or somatic BRCA1/2 mutations were analysed using $t$ tests for continuous variables and Fisher's exact test for categorical variables. Differences in $B R C A 1 / 2$ mutation testing rates for the stratification factors were analysed via Fisher's exact tests. Univariate logistic regression was used to evaluate the relationship between age and $B R C A 1 / 2$ mutation testing; odds ratios of $<1,1$ and $>1$ indicate lower, equal and higher odds of being tested, respectively, versus the reference value.

\section{Results}

\section{Patient demographics and clinical characteristics}

Records on 6161 adult women with HER2-negative ABC were provided by 742 oncologists, with 1285 and 4876 records from the US and EU5, respectively.

Demographics and baseline clinical characteristics by BRCA1/2 mutation testing (tested vs not tested) for 2015 and 2017 combined are provided in Table 1, with comparisons (tested vs not tested) by region in the supplementary material (Table A.1). The mean age was 63.4 years (58.3 vs 65.4 years in tested vs not tested); $75 \%$ of women had HRpositive/HER2-negative ABC, $23 \%$ had advanced TNBC and $2 \%$ had unknown HR status ABC. Women who were not tested for BRCA1/2 mutation were more likely to have HR-positive/HER2-negative ABC, have no known family history of breast or ovarian cancer, be postmenopausal, and be currently unemployed versus women who were tested (all $P<$ 0.0001). 
Table 1

Baseline demographics and clinical characteristics among adult women with HER2-negative ABC

\begin{tabular}{|c|c|c|c|}
\hline \multirow[t]{2}{*}{ Overall } & \multicolumn{2}{|l|}{$\begin{array}{l}\text { Total } \\
\mathrm{N}=6161\end{array}$} & \multirow[t]{2}{*}{ P-value } \\
\hline & $\begin{array}{l}\text { BRCA1/2 tested } \\
(n=1696)\end{array}$ & $\begin{array}{l}B R C A 1 / 2 \\
\text { not tested } \\
(n=4465)\end{array}$ & \\
\hline Mean age, years & 58.3 & 65.4 & $<0.0001$ \\
\hline \multicolumn{4}{|c|}{ Hormone receptor status, $n(\%)$} \\
\hline HR+/HER2- & $1067(63)$ & $3544(79)$ & $<0.0001$ \\
\hline TNBC & $577(34)$ & $838(19)$ & $<0.0001$ \\
\hline Unknown & $52(3)$ & $83(2)$ & 0.0039 \\
\hline Premenopausal, $n(\%)$ & $353(21)$ & $271(6)$ & $<0.0001$ \\
\hline \multicolumn{4}{|c|}{ Known family history of breast or ovarian cancer, $n(\%)$} \\
\hline Yes & $353(21)$ & $353(8)$ & $<0.0001$ \\
\hline No & $1171(69)$ & $3562(80)$ & $<0.0001$ \\
\hline Unknown & $172(10)$ & $550(12)$ & 0.0187 \\
\hline Currently employed, $n(\%)$ & $473(28)$ & $765(17)$ & $<0.0001$ \\
\hline \multicolumn{4}{|l|}{ Practice setting, $n(\%)^{\mathrm{b}}$} \\
\hline Academic & $914(54)$ & $2763(62)$ & \multirow[t]{2}{*}{$<0.0001$} \\
\hline Non-academic & $780(46)$ & $1696(38)$ & \\
\hline \multicolumn{4}{|c|}{ a $t$ test for continuous variables and Fisher's exact test for categorical variables. } \\
\hline \multicolumn{4}{|c|}{$\begin{array}{l}\text { bercentages based on patients for whom practice setting type was available (BRCA1/2 tested, } n=1694 ; B R C A 1 / 2 \\
\text { not tested, } n=4459 \text { ). }\end{array}$} \\
\hline \multicolumn{4}{|c|}{$\begin{array}{l}\text { ABC, advanced breast cancer; BRCA1/2, breast cancer susceptibility gene } 1 \text { or } 2 ; \mathrm{HER} 2 \text {, human epidermal growth } \\
\text { factor receptor 2; HER2-, HER2-negative; HR+, hormone receptor-positive; TNBC, triple-negative breast cancer. }\end{array}$} \\
\hline
\end{tabular}

\section{BRCA1/2 mutation testing rates by stratification factors}

Across all patients, the $B R C A 1 / 2$ mutation testing rate was found to be $28 \%$ (Fig. $1 \mathrm{a}$ ). Testing rates were significantly lower in the EU5 compared with the US (2015: $25 \%$ vs 57\%; 2017 : $17 \%$ vs $44 \%$; both years combined: $21 \%$ vs $50 \%$; all $P<$ 0.0001; Fig. 1). BRCA1/2 mutation testing rates decreased significantly between 2015 and 2017 in the US and EU5 combined (31\% vs $23 \%$ ) as well as in each region (all $P<0.0001)$.

Among the individual EU5 countries, and the US, the overall BRCA1/2 testing rates ranged from 14\% (UK) to 50\% (US). Testing rates varied across 2015 and 2017 in Germany (34\% vs. 25\%), Italy (33\% vs. 14\%), Spain (24\% vs. 15\%), UK (13\% vs. $15 \%)$, France ( $21 \%$ vs. $18 \%$ ), and the US ( $57 \%$ vs. $44 \%)$. Across all countries (except Italy), higher BRCA1/2 mutation testing rates were observed among patients with advanced TNBC vs patients with HR+/HER2- ABC. (Fig. 1). 
Lower BRCA1/2 mutation testing rates were generally observed in women with HR-positive/HER2-negative ABC versus those with TNBC, regardless of age, year, or region (Fig. 2). By year and region, the findings among all ages combined were consistent with the overall results, with significantly lower BRCA1/2 mutation testing rates in women with $\mathrm{HR}$ positive/HER2-negative $A B C$ versus those with TNBC.

Women aged $\geq 45$ years were less likely to have received $B R C A 1 / 2$ mutation testing than women aged $<45$ years (Table 2). This was observed among women with HR-positive/HER2-negative ABC, as well as among women with advanced TNBC, and in both regions.

Lower $B R C A 1 / 2$ mutation testing rates were also observed among women without versus with a known family history of breast or ovarian cancer (Fig. 3). This finding was consistent among different age groups with the exception of women with TNBC aged $\geq 65$ years (Fig. 3). Similarly, this finding was consistent across both regions with the exception of US women with TNBC (Fig. 3).

By physician practice setting, significantly fewer patients with HR-positive/HER2-negative ABC underwent $B R C A 1 / 2$ mutation testing at academic centres than in non-academic settings $(P<0.0001$; Fig. 4$)$. In contrast, for patients with TNBC, BRCA1/2 mutation testing rates were similar across both settings (Fig. 4). 
Table 2

Relationship between age and $B R C A 1 / 2$ mutation testing rate by HR status in adult women with HER2-negative ABC

\begin{tabular}{|c|c|c|c|c|c|c|c|c|c|}
\hline & \multicolumn{3}{|c|}{ HR+/HER2- } & \multicolumn{3}{|l|}{ TNBC } & \multicolumn{3}{|l|}{ Total } \\
\hline & $\begin{array}{l}B R C A 1 / 2 \\
\text { tested }\end{array}$ & $\begin{array}{l}\text { Odds } \\
\text { ratio }\end{array}$ & $P$-value & $\begin{array}{l}B R C A 1 / 2 \\
\text { tested }\end{array}$ & $\begin{array}{l}\text { Odds } \\
\text { ratio }\end{array}$ & $\begin{array}{l}P \text { - } \\
\text { value }\end{array}$ & $\begin{array}{l}B R C A 1 / 2 \\
\text { tested }\end{array}$ & $\begin{array}{l}\text { Odds } \\
\text { ratio }\end{array}$ & $P$-value \\
\hline & $n(\%)$ & & & $n(\%)$ & & & $n(\%)$ & & \\
\hline US & & $(n=963$ & & & $\begin{array}{l}(n= \\
295)\end{array}$ & & & $\begin{array}{l}(n= \\
1285)\end{array}$ & \\
\hline \multicolumn{10}{|l|}{$\begin{array}{l}\text { Age, } \\
\text { years }\end{array}$} \\
\hline$<45$ & $35(76)$ & 1.0 & REF & 38 (88) & 1.0 & REF & $74(81)$ & 1.0 & REF \\
\hline $45-54$ & $81(60)$ & 0.471 & 0.030 & $42(69)$ & 0.291 & 0.042 & 127 (63) & 0.394 & 0.002 \\
\hline $55-64$ & $157(54)$ & 0.371 & 0.007 & $62(59)$ & 0.291 & 0.031 & $226(58)$ & 0.320 & $\begin{array}{l}<.0001 \\
0.00\end{array}$ \\
\hline$\geq 65$ & $143(29)$ & 0.129 & $\begin{array}{l}<.001 \\
0.00\end{array}$ & $69(68)$ & 0.284 & 0.06 & 221 (37) & 0.132 & $\begin{array}{l}<.0001 \\
0.00\end{array}$ \\
\hline EU5 & & $\begin{array}{l}(n= \\
3648)\end{array}$ & & & $\begin{array}{l}(n= \\
1120)\end{array}$ & & & $\begin{array}{l}(n= \\
4876)\end{array}$ & \\
\hline \multicolumn{10}{|l|}{$\begin{array}{l}\text { Age, } \\
\text { years }\end{array}$} \\
\hline$<45$ & $67(38)$ & 1.0 & REF & 105 (64) & 1.0 & REF & $176(50)$ & 1.0 & REF \\
\hline $45-54$ & $124(29)$ & 0.667 & 0.041 & $108(46)$ & 0.490 & 0.001 & 236 (35) & 0.525 & $\begin{array}{l}< \\
0.0001\end{array}$ \\
\hline $55-64$ & 178 (19) & 0.378 & $<.001$ & $93(26)$ & 0.201 & $<0.001$ & $288(21)$ & 0.264 & $<.0001$ \\
\hline$\geq 65$ & $282(14)$ & 0.260 & $\begin{array}{l}< \\
0.001\end{array}$ & $60(16)$ & 0.113 & $<0.001$ & 348 (14) & 0.163 & $\begin{array}{l}< \\
0.0001\end{array}$ \\
\hline $\begin{array}{l}\text { Regions } \\
\text { combined }\end{array}$ & & $\begin{array}{l}(n= \\
4611)\end{array}$ & & & $\begin{array}{l}(n= \\
1415)\end{array}$ & & & $\begin{array}{l}(n= \\
6161)\end{array}$ & \\
\hline
\end{tabular}

Univariate logistic regression was used to evaluate the relationship between age and $B R C A 1 / 2$ mutation testing. Age is a categorical variable here and therefore patients aged $<45$ years have been used as the reference group/base. Each group is fit to the model as a separate covariate and the reported odds ratios measure the differences from the $<45$ age group.

$A B C$, advanced breast cancer; BRCA1/2, breast cancer susceptibility gene 1 or 2; EU5, France, Germany, Italy, Spain and the UK; HER2, human epidermal growth factor receptor 2; HER2-, HER2-negative; HR, hormone receptor; HR+, HRpositive; REF, reference category; TNBC, triple-negative breast cancer. 


\begin{tabular}{|c|c|c|c|c|c|c|c|c|c|}
\hline & \multicolumn{3}{|c|}{ HR+/HER2- } & \multicolumn{3}{|l|}{ TNBC } & \multicolumn{3}{|l|}{ Total } \\
\hline \multicolumn{10}{|l|}{$\begin{array}{l}\text { Age, } \\
\text { years }\end{array}$} \\
\hline$<45$ & $102(46)$ & 1.0 & REF & 143 (69) & 1.0 & REF & $250(57)$ & 1.0 & REF \\
\hline $45-54$ & $205(36)$ & 0.677 & 0.018 & $150(51)$ & 0.470 & $<0.001$ & $363(41)$ & 0.535 & $\begin{array}{l}< \\
0.001\end{array}$ \\
\hline $55-64$ & 335 (27) & 0.438 & $\begin{array}{l}< \\
0.001\end{array}$ & $155(35)$ & 0.241 & $<0.001$ & 514 (29) & 0.316 & $\begin{array}{l}< \\
0.001\end{array}$ \\
\hline$\geq 65$ & 425 (17) & 0.237 & $\begin{array}{l}< \\
0.001\end{array}$ & $129(28)$ & 0.175 & $<0.001$ & 569 (19) & 0.175 & $\begin{array}{l}< \\
0.001\end{array}$ \\
\hline \multicolumn{10}{|c|}{$\begin{array}{l}\text { Univariate logistic regression was used to evaluate the relationship between age and } B R C A 1 / 2 \text { mutation testing. Age } \\
\text { is a categorical variable here and therefore patients aged }<45 \text { years have been used as the reference group/base. } \\
\text { Each group is fit to the model as a separate covariate and the reported odds ratios measure the differences from the } \\
<45 \text { age group. }\end{array}$} \\
\hline \multicolumn{10}{|c|}{$\begin{array}{l}\text { ABC, advanced breast cancer; BRCA1/2, breast cancer susceptibility gene } 1 \text { or } 2 \text {; EU5, France, Germany, Italy, Spain } \\
\text { and the UK; HER2, human epidermal growth factor receptor } 2 \text {; HER2-, HER2-negative; HR, hormone receptor; HR+, HR- } \\
\text { positive; REF, reference category; TNBC, triple-negative breast cancer. }\end{array}$} \\
\hline
\end{tabular}

\section{Discussion}

This study assessed real-world patient demographics and BRCA1/2 mutation testing rates in 2015 and 2017 in over 6000 adult women with HER2-negative ABC in the US and EU5. Overall, the rate of BRCA1/2 mutation testing in this study was low (28\%); testing was significantly less frequent in the EU5 than in the US across both years. For both regions, the proportion of women with HER2-negative $A B C$ who received $B R C A 1 / 2$ mutation testing declined significantly from 2015 to 2017. This decrease may have been due to the approval of cyclin-dependent kinase (CDK)4/6 inhibitors, which became a new standard in combination with endocrine therapy during this same time period (starting in 2015/2016). Although CDK4/6 inhibitors can be used regardless of BRCA1/2 mutation status, optimal sequencing of PARP inhibitors (which were not available when this study was conducted) and CDK4/6 inhibitors has not been established in patients with BRCA1/2-mutated $A B C[4,28]$.

The lower rates of $B R C A 1 / 2$ mutation testing among women aged $\geq 45$ years, those with HR-positive/HER2-negative $A B C$ and those without a known family history of breast or ovarian cancer are consistent with the known risk factors for $B R C A 1 / 2$ mutations $[29,30]$. While many physicians may be aware of the higher risk groups, it is important to consider other patient populations, such as those with HR-positive/HER2-negative ABC. Only $23 \%$ of women with HRpositive/HER2-negative $A B C$ underwent $B R C A 1 / 2$ mutation testing, compared with $41 \%$ of patients with TNBC. The rate of $B R C A 1 / 2$ mutation testing among adult women with HR-positive/HER2-negative ABC was much lower in the EU5 than in the US, and was particularly low (16\%) among women with HR-positive/HER2-negative ABC in the EU5 without a known family history of these $B R C A 1 / 2$ mutation-related cancers. While germline $B R C A 1 / 2$ mutations are more common in patients with TNBC ( 10-15\% of unselected patients), they also occur in approximately $5 \%$ of unselected patients with HR-positive/HER2-negative ABC $[18,19,29]$. Moreover, because HR-positive BC accounts for $70-80 \%$ of all BC cases [31], it follows that numerically more patients with a BRCA1/2 mutation have HR-positive BC than TNBC. Increasing $B R C A 1 / 2$ mutation testing in this population is therefore an important and clinically meaningful consideration, particularly for patients without a known family history of breast or ovarian cancer, due to the lack of awareness for this patient group. 
BRCA1/2 mutation testing rates were largely similar between academic and non-academic settings for patients with TNBC, although a surprisingly lower rate of testing was observed in academic versus non-academic centres for the HRpositive/HER2-negative population. A recent study found that germline $B R C A 1 / 2$ mutation testing rates were significantly lower among oncologists in community practice than among those at academic medical centres [23]. Our results likely reflect the fact that oncologists were asked to exclude patients who were enrolled in clinical trials from the data they abstracted for this study, which may have caused bias in the data collected from academic centres.

Consistent with other studies [20-22], the overall $B R C A 1 / 2$ mutation testing rates observed in this study were low, indicating suboptimal uptake of BRCA1/2 mutation testing. Although the European Society for Medical Oncology guidelines available in 2015 and 2017 encouraged genetic testing and counselling to explore the possibility of hereditary $\mathrm{BC}[17,24,25]$, low uptake of $B R C A 1 / 2$ mutation testing in the EU5 was identified even among patients with a known family history of breast and/or ovarian cancer. Additionally, the varying rates of BRCA1/2 mutation testing across the US and EU5 and across the individual European countries is likely the result of different healthcare systems, local guidelines and policies. Therefore, there is a need to improve rates of $B R C A 1 / 2$ mutation testing through focused education about genetic risk, incidences of mutations in metastatic $B C$, testing pathways, reimbursement of testing, and availability and efficacy of PARP inhibitors. Increased awareness of recent guideline recommendations, especially following the approval and availability of targeted therapies, should also help to improve $B R C A 1 / 2$ mutation testing rates. It is possible that the disparity in BRCA1/2 mutation testing rates between the US and EU5, and across the individual European countries is likely the result of different healthcare systems, local guidelines, policies, and renumeration aspects. A systematic review of international guidelines on screening and management of BRCA-mutant BC published between January 2007 and February 2018 identified regional and organisational differences regarding genetic screening, counselling and treatment of BRCA1/2-mutant BC [32]. Genetic testing guidelines have also evolved over time, with more recent guidelines advocating broader criteria regarding family history [32]. Overall, a greater consensus and harmonisation of guidelines across geographic regions may help to optimise identification and management of patients with HER2-negative BC harbouring BRCA1/2 mutations [32].

Another development that might positively affect $B R C A 1 / 2$ mutation testing rates is the availability of next-generation sequencing, which enables simultaneous sequencing of multiple cancer susceptibility genes and may be more efficient, faster and less expensive than testing for individual genes [33]. A recent cost-effectiveness analysis found that, compared with $B R C A 1 / 2$ mutation testing based on clinical criteria or family history, multigene testing of $B R C A 1 / 2$ and $P A L B 2$ in unselected patients with $B C$ could reduce $B C$ incidence and mortality, and would be cost-effective for UK and US healthcare systems [34]. Although the diagnostic and prognostic implications for many genes on existing multigene panels are not yet clear [4,35], the potential for simultaneous detection of pathogenic variants other than $B R C A 1 / 2$ may influence future uptake of genetic testing.

Key strengths of this study are that it included a relatively large sample $(>6000)$ of unselected patients treated in realworld clinical practice and captured data from multiple countries and across two distinct time periods. Analysis of patient demographics also allowed evaluation of the relationship between age and BRCA1/2 mutation testing. Because patient charts were randomly sampled, this analysis likely accurately reflects $B R C A 1 / 2$ mutation testing in selected US and EU5 patient populations. Nonetheless, the study has some limitations relating to the self-reported nature of the data, as no independent verification was possible. Accuracy of the collected data was dependent on reporting by the physician and patient, and recall bias or missing information may have existed. All data were anonymised and aggregated prior to analysis; therefore, it was not possible to prevent double counting of patients in 2015 and 2017 . The study was also more likely to collect data on patients who consult their physician more frequently. Of note, data collection in 2015/2017 was conducted before the US and EU approvals of PARP inhibitors for BRCA1/2-mutated HER2negative $A B C$; thus, the therapeutic utility of $B R C A 1 / 2$ mutation testing at the time was limited to informing patient eligibility for platinum-based chemotherapy, along with the aforementioned advantages for identification of familial risk, 
planning of intensified follow-up care and early detection of ovarian cancer [16, 17, 32, 36, 37]. It will therefore be interesting to evaluate patterns of $B R C A 1 / 2$ mutation testing in the PARP inhibitor era to determine whether uptake is increasing following the availability of targeted treatments. Finally, BRCA1/2 mutation testing in the current study was not confined to testing for germline BRCA1/2 mutations, and germline and somatic BRCA1/2 mutations were not differentiated; therefore, some reports may have been for somatic $B R C A 1 / 2$ mutations. The therapeutic implications of somatic BRCA1/2 mutations are not clear, as PARP inhibitors are approved only for HER2-negative ABC harbouring germline $B R C A 1 / 2$ mutations $[4,10,11,13,14]$.

In summary, BRCA1/2 mutation testing rates were low in this study, and disparities in testing were observed, including between years (2015 vs 2017) and regions (US vs EU5). BRCA1/2 mutation testing rates also varied with certain demographic and baseline characteristics, including age, HR status and family history of breast or ovarian cancer, consistent with previous reports [20,30]. Opportunities exist to increase $B R C A 1 / 2$ mutation testing in patients with $A B C$, regardless of physician setting and particularly among those with HR-positive/HER2-negative disease, patients aged $\geq$ 45 years and patients without a known family history of breast or ovarian cancer. Hence, educational efforts about therapeutic implications, remuneration of testing and genetic regulations are needed to increase oncologists' awareness about the relevance of $B R C A 1 / 2$ mutation testing in the context of therapeutic decision making, particularly in the EU5 region. Further studies evaluating trends in germline-specific BRCA1/2 mutation testing are also warranted.

\section{Declarations}

\section{Funding}

This study was sponsored by Pfizer Inc.

\section{Conflict of interest:}

Michael Patrick Lux: reports honoraria for lectures, consulting or advisory role for AstraZeneca, Eisai, Eli Lilly, Exact Sciences, Hexal, Medac, MSD, Novartis, Pfizer, Roche, Pierre Fabre and PharmaMar; travel, accommodations and expenses from Pfizer and Roche; editorial board member of Medac; fees for non-CME services from AstraZeneca, Eisai, Eli Lilly, Exact Sciences, MSD, Novartis, Pfizer and Roche. Katie Lewis and Alex Rider: employees of Adelphi Real World, which received financial support from Pfizer for the development of this manuscript. Alexander Niyazov: employee of and owns stock in Pfizer Inc.

\section{Availability of data and materials}

Publication of study results was not contingent on the sponsor's approval or censorship of the manuscript.

All data that support the findings of this study are the intellectual property of Adelphi Real World. All requests for access should be addressed directly to Katie Lewis at katie.lewis@adelphigroup.com.

\section{Authors' contribution}

Guarantor of integrity of the entire study: AN

Study concepts and design: AN, MPL, KL, AR

Literature research: $A N, M P L, K L, A R$

Experimental studies/data analysis: $A N, M P L, K L, A R$

Page 10/17 
Statistical analysis: KL

Manuscript preparation: MPL, KL, AR, AN

Manuscript editing: MPL, KL, AR, AN

Ethics approval

All data were anonymised and aggregated prior to analysis. Data collection in the 2017 wave received ethical approval from the Freiburger Ethik-Kommission International and the Western Institutional Review Board.

\section{Consent to participate and publication}

Using a check box, patients provided informed consent for use of their anonymized and aggregated data for research and publication in scientific journals. Data were collected in such a way that patients and physicians could not be identified directly; all data were aggregated and de-identified before receipt.

\section{Acknowledgements}

Statistical support was provided by Lucy Massy of Adelphi Real World, which received financial support from Pfizer for the development of this manuscript. Medical writing support was provided by James Balwit, MS, CMPP, of CMC AFFINITY, McCann Health Medical Communications, and was funded by Pfizer.

\section{References}

1. Paul A, Paul S (2014) The breast cancer susceptibility genes (BRCA) in breast and ovarian cancers. Front Biosci (Landmark Ed) 19:605-618

2. Mersch J, Jackson MA, Park M, Nebgen D, Peterson SK, Singletary C et al (2015) Cancers associated with BRCA1 and BRCA2 mutations other than breast and ovarian. Cancer 121:269-275

3. Cavanagh $\mathrm{H}$, Rogers KM (2015) The role of BRCA1 and BRCA2 mutations in prostate, pancreatic and stomach cancers. Hered Cancer Clin Pract 13:16

4. Cardoso F, Senkus E, Costa A, Papadopoulos E, Aapro M, André F et al (2018) 4th ESO-ESMO International Consensus Guidelines for Advanced Breast Cancer (ABC 4)†. Ann Oncol 29:1634-1657

5. National Comprehensive Cancer Network (NCCN). NCCN Clinical Practice Guidelines in Oncology (NCCN Guidelines $\left.{ }^{\circledR}\right)$ : Breast Cancer. Version 5. Available at: https://www.nccn.org/professionals/physician_gls/pdf/breast_blocks.pdf; 2020. Accessed 26 March 2021

6. Egger SJ, Willson ML, Morgan J, Walker HS, Carrick S, Ghersi D et al (2017) Platinum-containing regimens for metastatic breast cancer. Cochrane Database Syst Rev 6:CD003374

7. Robson M, Im S-A, Senkus E, Xu B, Domchek SM, Masuda N et al (2017) Olaparib for Metastatic Breast Cancer in Patients with a Germline BRCA Mutation. N Engl J Med 377:523-533

8. Litton JK, Rugo HS, Ettl J, Hurvitz SA, Gonçalves A, Lee K-H et al (2018) Talazoparib in patients with advanced breast cancer and a germline BRCA mutation. N Engl J Med 379:753-763

9. European Medicines Agency. Assessment report: Talzenna [Procedure No. EMEA/H/C/004674/0000]. Available at: https://www.ema.europa.eu/en/documents/assessment-report/talzenna-epar-public-assessment-report_en.pdf; 2019. Accessed 26 March 2021

10. European Medicines Agency. TALZENNA® (talazoparib) Summary of Product Characteristics. Available at: https://www.ema.europa.eu/en/documents/product-information/talzenna-epar-product-information_en.pdf; 2019. 
Accessed 26 March 2021

11. U.S. Food and Drug Administration. TALZENNA® (talazoparib) prescribing information. Available at: http://labeling.pfizer.com/ShowLabeling.aspx?id=11046; 2020. Accessed 26 March 2021

12. European Medicines Agency. Assessment report: Lynparza [Procedure No. EMEA/H/C/003726/II/0020]. Available at: https://www.ema.europa.eu/en/documents/variation-report/lynparza-h-c-3726-ii-0020-epar-assessment-reportvariation_en.pdf; 2019. Accessed 26 March 2021

13. European Medicines Agency. LYNPARZA® (olaparib) Summary of Product Characteristics. Available at: https://www.medicines.org.uk/emc/product/9204/smpc; 2019. Accessed 26 March 2021

14. U.S. Food and Drug Administration. LYNPARZA® (olaparib) prescribing information. Available at: https://www.azpicentral.com/lynparza_tb/lynparza_tb.pdf\#page=1; 2020. Accessed 26 March 2021

15. National Comprehensive Cancer Network (NCCN). NCCN Clinical Practice Guidelines in Oncology (NCCN Guidelines $\left.{ }^{\circledR}\right)$ : Genetic/familial high-risk assessment: breast, ovarian, and pancreatic. Version 1. Available at: https://www.nccn.org/professionals/physician_gls/pdf/genetics_bop.pdf; 2021. Accessed 26 March 2021

16. Ditsch N, Untch M, Thill M, Müller V, Janni W, Albert US et al (2019) AGO Recommendations for the Diagnosis and Treatment of Patients with Early Breast Cancer: Update 2019. Breast Care (Basel) 14:224-245

17. Paluch-Shimon S, Cardoso F, Sessa C, Balmana J, Cardoso MJ, Gilbert F et al (2016) Prevention and screening in BRCA mutation carriers and other breast/ovarian hereditary cancer syndromes: ESMO Clinical Practice Guidelines for cancer prevention and screening. Ann Oncol 27(Suppl 5):v103-v1v10

18. Fasching PA, Yadav S, Hu C, Wunderle M, Häberie L, Hart SN et al (2021) Mutations in BRCA1/2 and Other Panel Genes in Patients With Metastatic Breast Cancer-Association With Patient and Disease Characteristics and Effect on Prognosis. J Clin Oncol 39:1619-1630

19. Armstrong N, Ryder S, Forbes C, Ross J, Quek RG (2019) A systematic review of the international prevalence of BRCA mutation in breast cancer. Clin Epidemiol 11:543-561

20. Kurian AW, Ward KC, Howlader N, Deapen D, Hamilton AS, Mariotto A et al (2019) Genetic Testing and Results in a Population-Based Cohort of Breast Cancer Patients and Ovarian Cancer Patients. J Clin Oncol 37:1305-1315

21. Childers CP, Childers KK, Maggard-Gibbons M, Macinko J (2017) National Estimates of Genetic Testing in Women With a History of Breast or Ovarian Cancer. J Clin Oncol 35:3800-3806

22. Quek RGW, Mardekian J. Clinical, Outcomes (2019) Treatment Patterns, and Health Resource Utilization Among Metastatic Breast Cancer Patients with Germline BRCA1/2 Mutation: A Real-World Retrospective Study. Adv Ther $36: 708-720$

23. Mahtani RL, Niyazov A, Lewis K, Wild R, Rider A, Arondekar B et al (2020) Germline BRCA1/2 (gBRCA1/2) testing patterns among oncologists (ONC) treating HER2- advanced breast cancer (ABC): Results from a multi-country realworld study. Ann Oncol 31(Suppl 2):S62-S Abstract 157P.

24. Senkus E, Kyriakides S, Ohno S, Penault-Llorca F, Poortmans P, Rutgers E et al (2015) Primary breast cancer: ESMO Clinical Practice Guidelines for diagnosis, treatment and follow-up. Ann Oncol 26(Suppl 5):v8-30

25. Senkus E, Kyriakides S, Penault-Llorca F, Poortmans P, Thompson A, Zackrisson S et al (2013) Primary breast cancer: ESMO Clinical Practice Guidelines for diagnosis, treatment and follow-up. Ann Oncol 24(Suppl 6):vi7-23

26. The American Society of Breast Surgeons. Consensus Guideline on Genetic Testing for Hereditary Breast Cancer. Available at: https://www.breastsurgeons.org/docs/statements/Consensus-Guideline-on-Genetic-Testing-forHereditary-Breast-Cancer.pdf; 2019. Accessed January 05, 2021

27. Tung NM, Boughey JC, Pierce LJ, Robson ME, Bedrosian I, Dietz JR et al (2020) Management of hereditary breast cancer: American Society of Clinical Oncology, American Society for Radiation Oncology, and Society of Surgical Oncology Guideline. J Clin Oncol 38:2080-2106

Page 12/17 
28. Thomssen C, Lüftner D, Untch M, Haidinger R, Würstlein R, Harbeck N et al. International Consensus Conference for Advanced Breast Cancer, Lisbon 2019: ABC5 Consensus - Assessment by a German Group of Experts [Conference Report]. Breast Care. 2020;15:82-95

29. Couch FJ, Hart SN, Sharma P, Toland AE, Wang X, Miron P et al (2015) Inherited mutations in 17 breast cancer susceptibility genes among a large triple-negative breast cancer cohort unselected for family history of breast cancer. J Clin Oncol 33:304-311

30. Li J, Wen WX, Eklund M, Kvist A, Eriksson M, Christensen HN et al (2019) Prevalence of BRCA1 and BRCA2 pathogenic variants in a large, unselected breast cancer cohort. Int J Cancer 144:1195-1204

31. Dobovišek L, Krstanović F, Borštnar S, Debeljak N (2020) Cannabinoids and Hormone Receptor-Positive Breast Cancer Treatment. Cancers (Basel) 12:525

32. Forbes C, Fayter D, de Kock S, Quek RG (2019) A systematic review of international guidelines and recommendations for the genetic screening, diagnosis, genetic counseling, and treatment of $B R C A$-mutated breast cancer. Cancer Manag Res 11:2321-2337

33. Tung N, Battelli C, Allen B, Kaldate R, Bhatnagar S, Bowles K et al (2015) Frequency of mutations in individuals with breast cancer referred for $B R C A 1$ and $B R C A 2$ testing using next-generation sequencing with a 25-gene panel. Cancer 121:25-33

34. Sun L, Brentnall A, Patel S, Buist DSM, Bowles EJA, Evans DGR et al (2019) A Cost-effectiveness Analysis of Multigene Testing for All Patients With Breast Cancer. JAMA Oncol 5:1718-1730

35. Pal T, Agnese D, Daly M, La Spada A, Litton J, Wick M et al (2020) Points to consider: is there evidence to support $B R C A 1 / 2$ and other inherited breast cancer genetic testing for all breast cancer patients? A statement of the American College of Medical Genetics and Genomics (ACMG). Genet Med 22:681-685

36. Cardoso F, Costa A, Norton L, Senkus E, Aapro M, André F et al (2014) ESO-ESMO 2nd international consensus guidelines for advanced breast cancer (ABC2)†. Ann Oncol 25:1871-1888

37. Cardoso F, Costa A, Senkus E, Aapro M, André F, Barrios CH et al (2017) 3rd ESO-ESMO International Consensus Guidelines for Advanced Breast Cancer (ABC 3). Ann Oncol 28:16-33

\section{Figures}


TOTAL SAMPLE

\begin{tabular}{|c|c|c|c|c|c|c|c|c|c|}
\hline \multirow{3}{*}{$\begin{array}{r}\text { ALL } \\
\text { PATIENTS }\end{array}$} & Total $(n=6161)$ & $28 \%$ & $72 \%$ & Total $(n=4611)$ & $23 \%$ & $77 \%$ & Total $(n=1415)$ & $41 \%$ & $59 \%$ \\
\hline & $2015(n=3318)$ & $31 \%$ & $69 \%$ & $2015(n=2352)$ & $28 \%$ & $72 \%$ & $2015(n=863)$ & $40 \%$ & $60 \%$ \\
\hline & $2017(n=2843)$ & $23 \%$ & $77 \%$ & $2017(n=2259)$ & $18 \%$ & $82 \%$ & $2017(n=552)$ & $42 \%$ & $58 \%$ \\
\hline \multirow{3}{*}{ US } & Total $(n=1285)$ & $50 \%$ & $50 \%$ & Total $(n=963)$ & $43 \%$ & $57 \%$ & Total $(n=295)$ & & $28 \%$ \\
\hline & $2015(n=657)$ & $57 \%$ & $43 \%$ & $2015(n=470)$ & $51 \%$ & $49 \%$ & $2015(n=171)$ & & $29 \%$ \\
\hline & $2017(n=628)$ & $44 \%$ & $56 \%$ & $2017(n=493)$ & $36 \%$ & $64 \%$ & $2017(n=124)$ & & $27 \%$ \\
\hline \multirow{3}{*}{ EU5 } & Total $(n=4876)$ & $21 \%$ & $79 \%$ & Total $(n=3648)$ & $18 \%$ & $82 \%$ & Total $(n=1120)$ & $33 \%$ & $67 \%$ \\
\hline & $2015(n=2661)$ & $25 \%$ & $75 \%$ & $2015(n=1882)$ & $23 \%$ & $77 \%$ & $2015(n=692)$ & $33 \%$ & $67 \%$ \\
\hline & $2017(n=2215)$ & $17 \%$ & $83 \%$ & $2017(n=1766)$ & $13 \%$ & $87 \%$ & $2017(n=428)$ & $33 \%$ & $67 \%$ \\
\hline \multirow{3}{*}{ France } & Total $(n=1004)$ & $20 \%$ & $81 \%$ & Total $(n=778)$ & $15 \%$ & $85 \%$ & Total $(n=226)$ & $34 \%$ & $66 \%$ \\
\hline & 2015 (n=535) & $21 \%$ & $79 \%$ & $2015(n=392)$ & $18 \%$ & $82 \%$ & $2015(n=143)$ & $29 \%$ & $71 \%$ \\
\hline & $2017(n=469)$ & $18 \%$ & $82 \%$ & $2017(n=386)$ & $13 \%$ & $87 \%$ & $2017(n=83)$ & $42 \%$ & $58 \%$ \\
\hline \multirow{3}{*}{ Germany } & Total $(n=990)$ & $30 \%$ & $70 \%$ & Total $(n=692)$ & $26 \%$ & $74 \%$ & Total $(n=297)$ & $38 \%$ & $62 \%$ \\
\hline & $2015(n=557)$ & $34 \%$ & $66 \%$ & $2015(n=379)$ & $30 \%$ & $70 \%$ & $2015(n=178)$ & $43 \%$ & $57 \%$ \\
\hline & $2017(n=433)$ & $25 \%$ & $75 \%$ & $2017(n=313)$ & $22 \%$ & $78 \%$ & $2017(n=119)$ & $30 \%$ & $70 \%$ \\
\hline \multirow{3}{*}{ Italy } & Total $(n=939)$ & $24 \%$ & $76 \%$ & Total $(n=686)$ & $25 \%$ & $75 \%$ & Total $(n=156)$ & $19 \%$ & $81 \%$ \\
\hline & $2015(n=512)$ & $33 \%$ & $67 \%$ & $2015(n=345)$ & $38 \%$ & $62 \%$ & $2015(n=83)$ & $27 \%$ & $73 \%$ \\
\hline & $2017(n=427)$ & $14 \%$ & $86 \%$ & $2017(n=341)$ & $11 \%$ & $89 \%$ & $2017(n=73)$ & $11 \%$ & $89 \%$ \\
\hline \multirow{3}{*}{ Spain } & Total (n=1029) & $20 \%$ & $80 \%$ & Total $(n=774)$ & $15 \%$ & $85 \%$ & Total $(n=253)$ & $35 \%$ & $65 \%$ \\
\hline & $2015(n=566)$ & $24 \%$ & $76 \%$ & $2015(n=402)$ & $20 \%$ & $80 \%$ & $2015(n=164)$ & $32 \%$ & $68 \%$ \\
\hline & $2017(n=463)$ & $15 \%$ & $85 \%$ & $2017(n=372)$ & $9 \%$ & $91 \%$ & $2017(n=89)$ & $40 \%$ & $60 \%$ \\
\hline \multirow{3}{*}{ UK } & Total $(n=914)$ & $14 \%$ & $86 \%$ & Total $(\mathrm{N}=718)$ & $9 \%$ & $91 \%$ & Total $(n=188)$ & $31 \%$ & $69 \%$ \\
\hline & $2015(n=491)$ & $13 \%$ & $87 \%$ & $2015(n=364)$ & $9 \%$ & $91 \%$ & $2015(n=124)$ & $27 \%$ & $73 \%$ \\
\hline & $2017(n=423)$ & $15 \%$ & $85 \%$ & $2017(n=354)$ & $9 \%$ & $91 \%$ & $2017(n=64)$ & $39 \%$ & $61 \%$ \\
\hline
\end{tabular}

\section{Figure 1}

BRCA1/2 mutation testing rates by region year, and HR status in adult women with HER2-negative ABC. 
HR+/HER2-
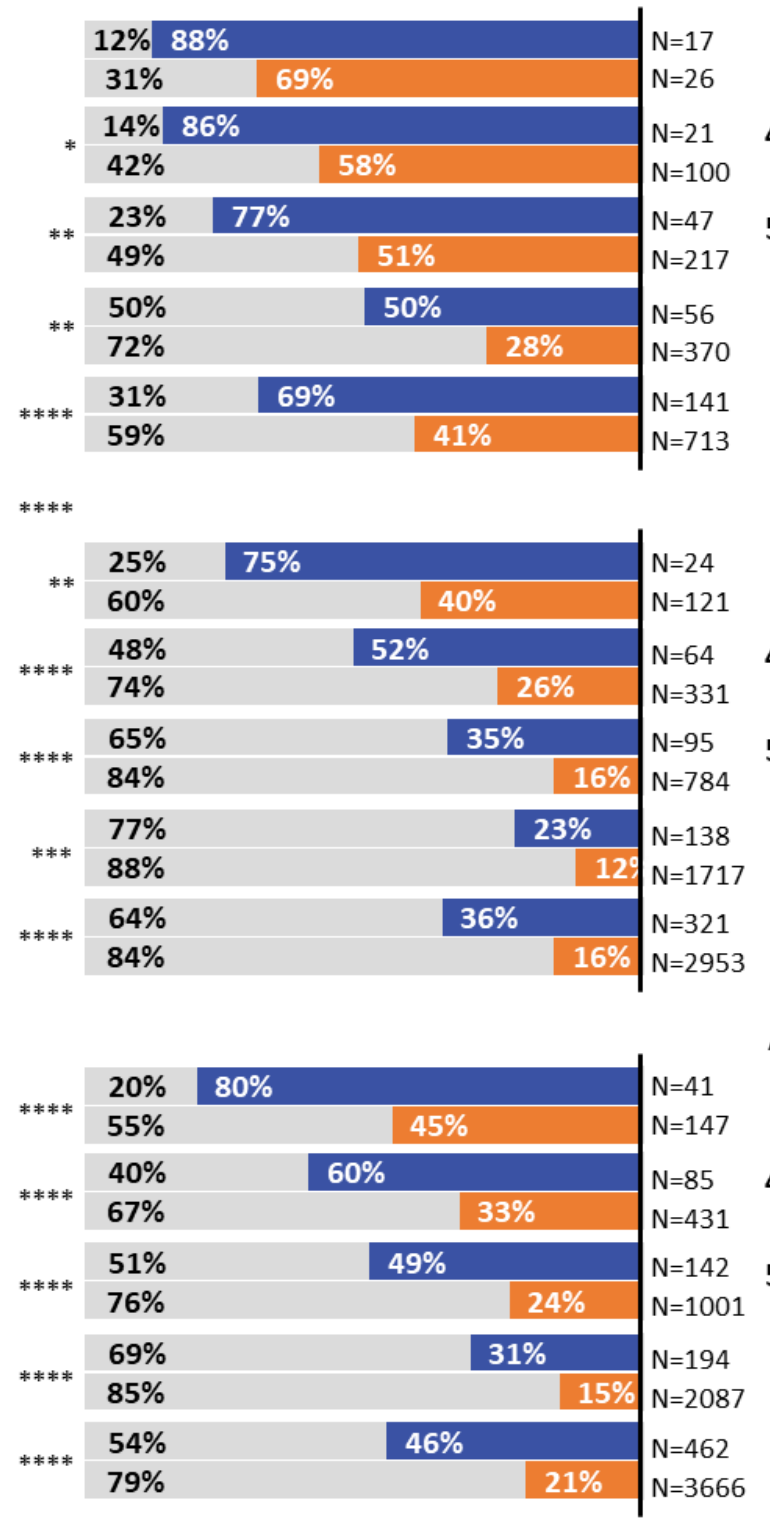

\section{US}

$<45$ years old

45-54 years old

55-64 years old

$\geq 65$ years old

All

\section{EU5}

$<45$ years old

45-54 years old

55-64 years old

$\geq 65$ years old

All

All patients

$<45$ years old

45-54 years old

55-64 years old

$\geq 65$ years old

All
$B R C A 1 / 2$ tested (family history)

BRCA1/2 tested (no family history)

$B R C A 1 / 2$ not tested

TNBC
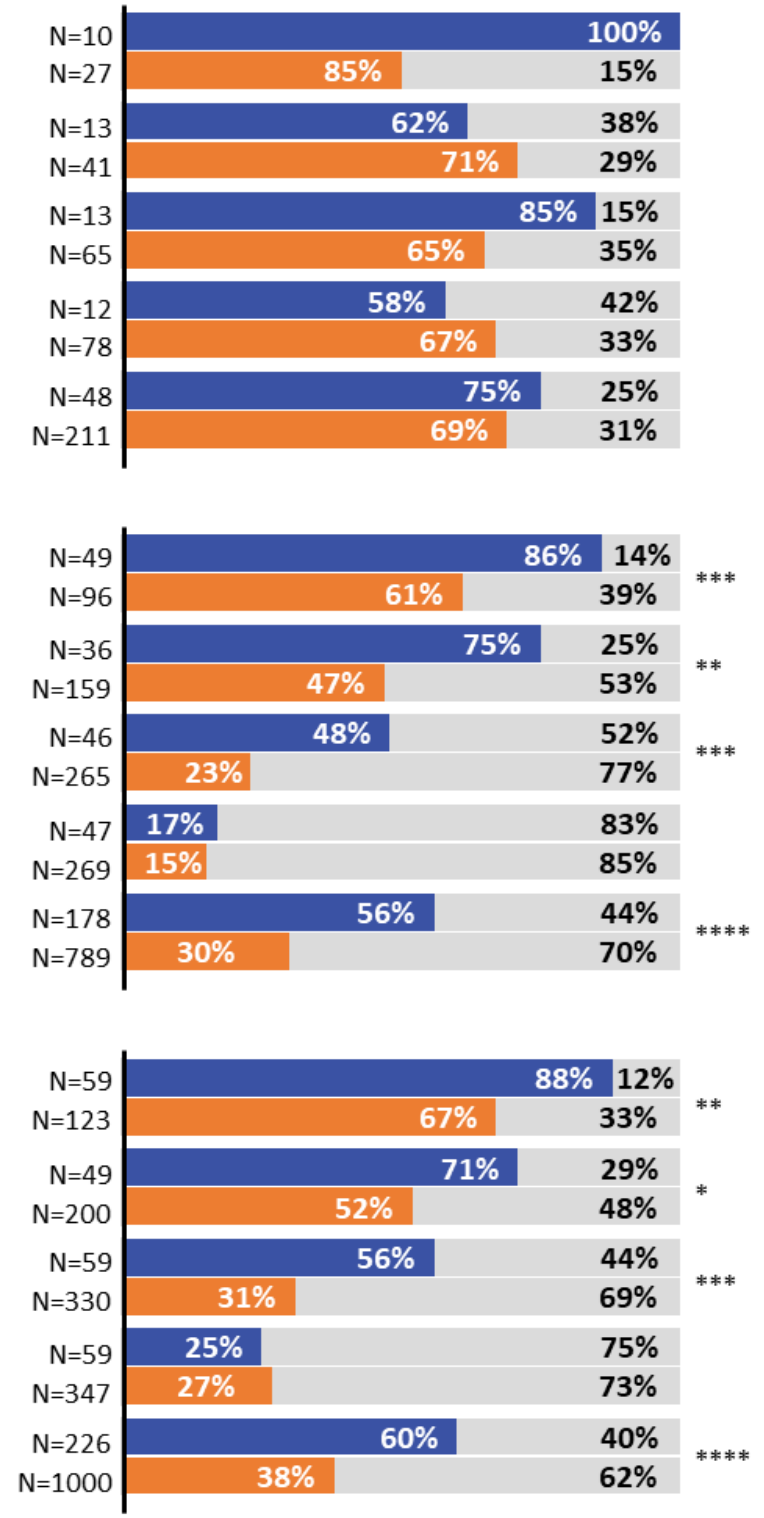

Figure 2

BRCA1/2 mutation testing rates by HR status, year, region and age in adult women with HER2-negative ABC. 
2015
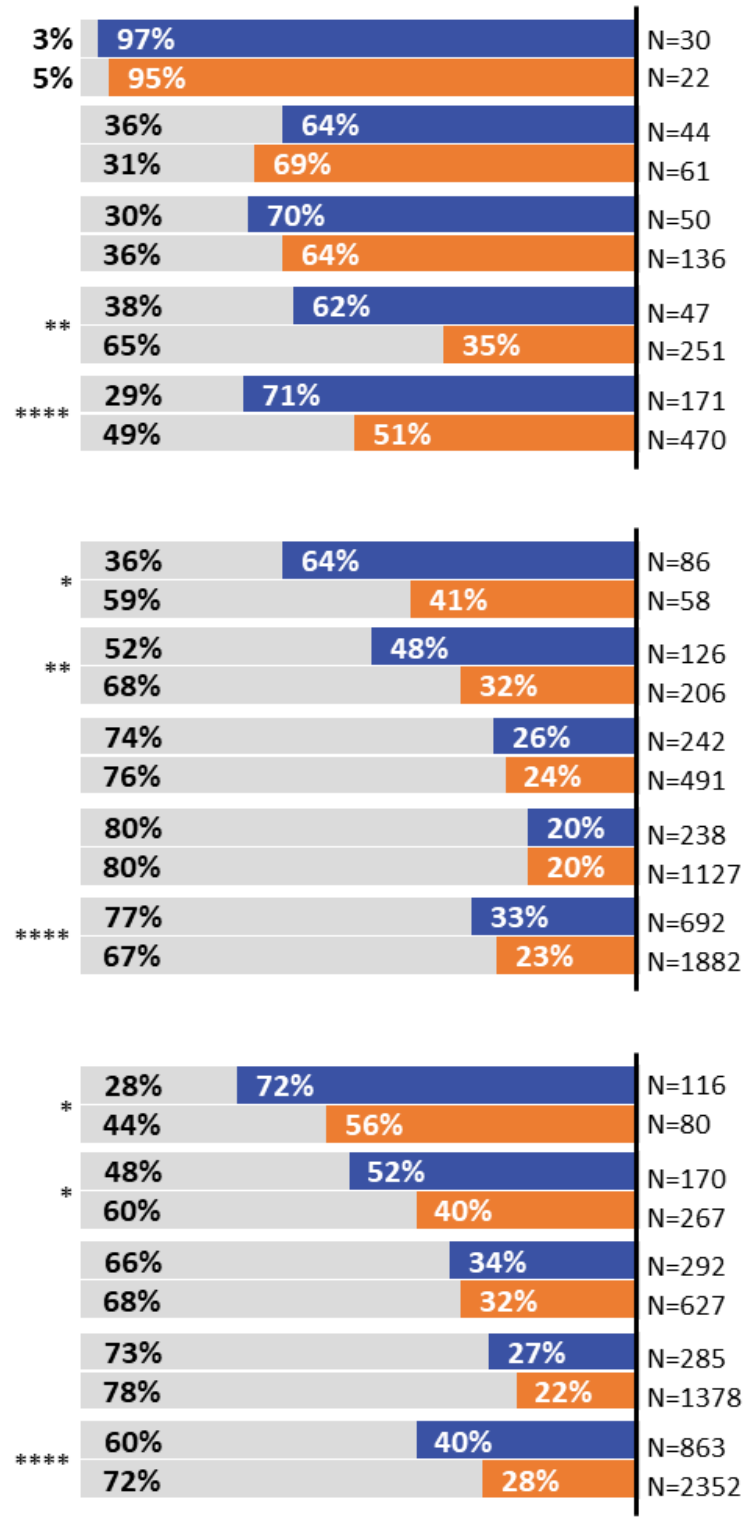

US

$<45$ years old

45-54 years old

55-64 years old

$\geq 65$ years old

All

\section{EU5}

$<45$ years old

45-54 years old

$55-64$ years old

$\geq 65$ years old

All

All patients

$<45$ years old

45-54 years old

55-64 years old

$\geq 65$ years old

All
BRCA1/2 tested (TNBC)

BRCA1/2 tested (HR+/HER2-)

$B R C A 1 / 2$ not tested

2017

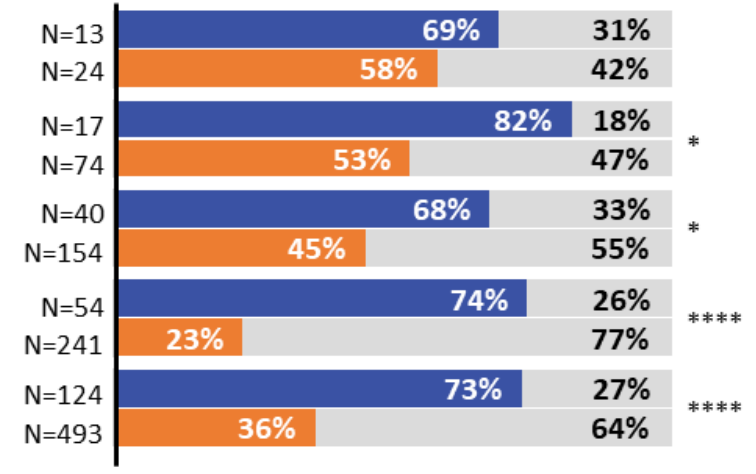

\begin{tabular}{|c|c|c|}
\hline $\mathrm{N}=79$ & $63 \%$ & $37 \%$ \\
\hline $\mathrm{N}=120$ & $36 \%$ & $64 \%$ \\
\hline $\mathrm{N}=108$ & $44 \%$ & $56 \%$ \\
\hline $\mathrm{N}=226$ & $26 \%$ & $74 \%$ \\
\hline $\mathrm{N}=115$ & $26 \%$ & $74 \%$ \\
\hline $\mathrm{N}=468$ & $13 \%$ & $87 \%$ \\
\hline $\mathrm{N}=126$ & $10 \%$ & $90 \%$ \\
\hline $\mathrm{N}=952$ & $6 \%$ & $94 \%$ \\
\hline $\mathrm{N}=428$ & $33 \%$ & $67 \%$ \\
\hline $\mathrm{N}=1766$ & $13 \%$ & $87 \%$ \\
\hline
\end{tabular}

\begin{tabular}{|c|c|c|}
\hline $\mathrm{N}=92$ & $64 \%$ & $36 \%$ \\
\hline $\mathrm{N}=144$ & $40 \%$ & $60 \%$ \\
\hline $\mathrm{N}=125$ & $49 \%$ & $51 \%$ \\
\hline $\mathrm{N}=300$ & $33 \%$ & $67 \%$ \\
\hline$N=155$ & $37 \%$ & $63 \%$ \\
\hline $\mathrm{N}=622$ & $21 \%$ & $79 \%$ \\
\hline $\mathrm{N}=180$ & $29 \%$ & $71 \%$ \\
\hline $\mathrm{N}=1193$ & $10 \%$ & $90 \%$ \\
\hline$N=552$ & $42 \%$ & $58 \%$ \\
\hline$N=2259$ & $18 \%$ & $82 \%$ \\
\hline
\end{tabular}

Figure 3

BRCA1/2 mutation testing rates by known family history of breast or ovarian cancer, HR status, region and age in adult women with HER2-negative ABC. 


\section{HR+/HER2-}

Academic

\section{Non-academic}
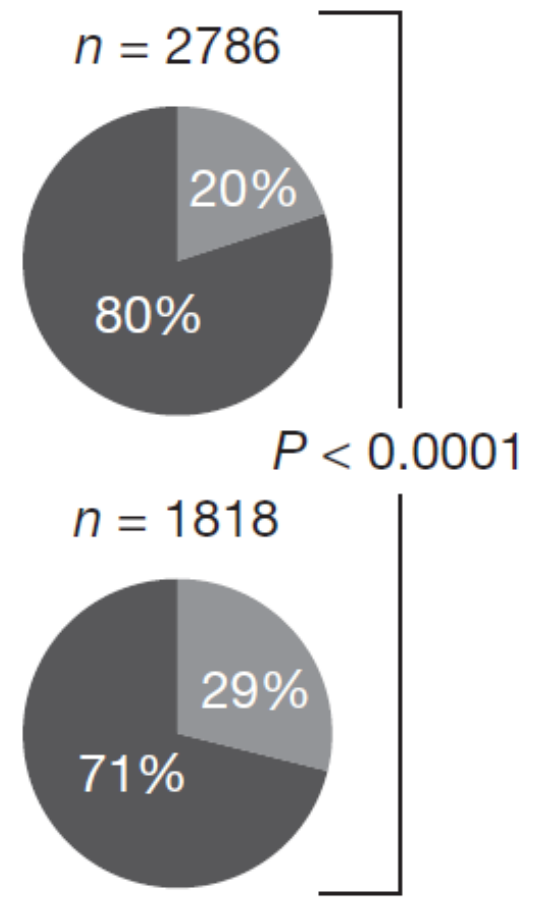

Total

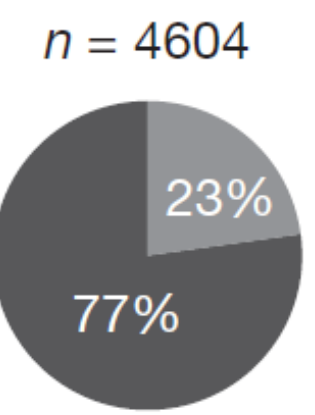

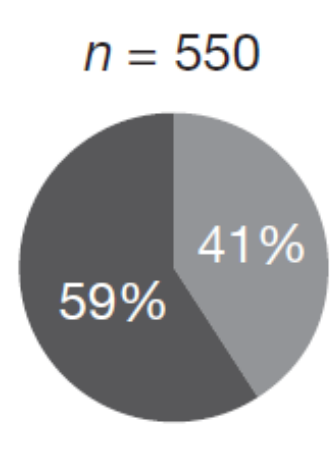

\section{TNBC}
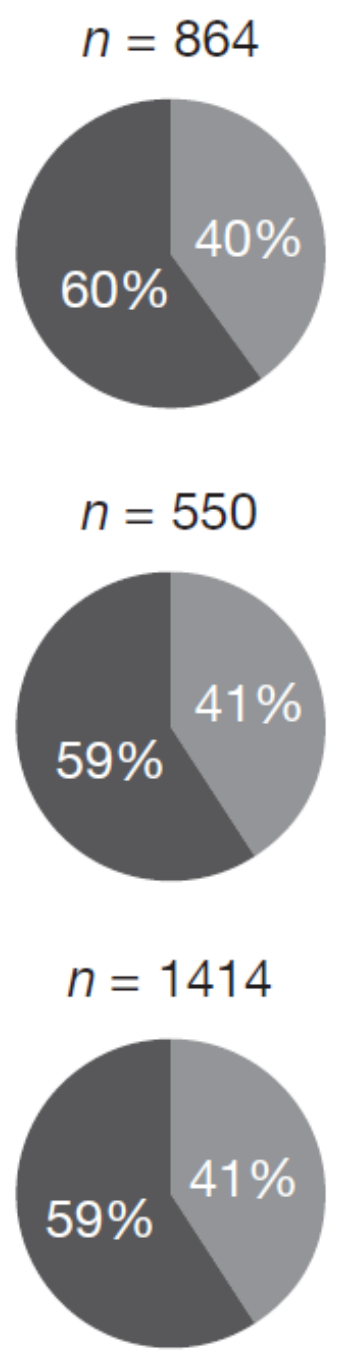

Figure 4

BRCA1/2 mutation testing rates by HR status and physician practice setting in adult women with HER2-negative ABC.

\section{Supplementary Files}

This is a list of supplementary files associated with this preprint. Click to download.

- AppendixA.docx 